\title{
Responsible innovation as a path toward prosperity
}

\section{Opinion}

One day we might look back to last era and notice that there were a huge development and progress due to the contribution of responsible innovation (RI). The responsible innovation is described as a fundamental object and factor for the evolution, development and success. In addition to the remarkable advances of the modern era, every profession has undergone a responsible innovation with high ethics which surely lead and drive to improve many sectors (Including computer sciences, political sciences, sociology and management sciences, bioethics, philosophy, theology, law and medicine).The responsible innovation is among the most important approaches to shape and improve the public sector, the life quality, spread the satisfaction and the equality between people and boost the global conditions. ${ }^{1-3}$

We highlight the meaningful substance of the innovation, according to Schumpeter, economic performance describes the purpose of innovation as really a serious topic especially because its differences depending on the sight of the observer. However, in order to find out the essential values which we are expecting the innovation and development to consider, we will be able to design the form of the RI purpose and objective. The main purpose of the RI is to serve society and humanity. Because RI is an issue linked to sustainable development and economic growth, therefore the European Union has stated and proclaimed that the RI gives birth to competitive social market economy. Via being responsibility-driven and assert the right impacts, it means where there are an under disciplinary team which works with high ethics and responsibility, it will surely lead to good outcomes to the company as well as the country and reassure the financial growth and sustainability and an economic evolution by its credibility and reputation in the domestic and the international market and gaining the public trust which enhances the economic sector and boosts its growth. ${ }^{4}$

The RI reflects the essential values that Rene Von Schomberg described (Responsible Research and Innovation is a transparent, interactive process by which societal actors and innovators become mutually responsive to each other with a view on the (ethical) acceptability, sustainability and societal desirability of the innovation process and its marketable products (in order to allow a proper embedding of scientific and technological advances in our society). ${ }^{5}$ According to Von Schomberg, responsible innovation overlay various area of elements, some are combined and connected, and some are specified, so the substantial features are the responsibility measures and the major fields of interests, responsible innovation give us a sight of commitment and obligation toward the future by reassuring and covering particular sectors of interest, ethical and social parts during the innovation process and the method which is taking place in the present. The environmental awareness (conscious) or in another term the perspective approach is among the most common measures between all the participants which is also reflected on a certain stage in the approval and policy standards. It is seen as a key and motive to social and ethical corporation and gives birth to the workers diversity because the diversity is a critical issue of productivity, flexibility and adaptation. Thus, the innovation systems will be
Volume 5 Issue I - 2018

\author{
Kadour Ghanemi,' Shuangsheng Yan ${ }^{1,2}$ \\ 'Department of Business Management, China Pharmaceutical \\ University, China \\ ${ }^{2}$ Department of Social Science, China Pharmaceutical University, \\ China
}

Correspondence: Shuangsheng Yan, Associate Professor, Director, the Philosophy of Teaching and Research Office, Department of Social Science, International Pharmaceutical Business School, China Pharmaceutical University, No 639, Longmian Avenue, Jiangning District, Nanjing, PR China, 2 I I 198 , Tel +86 I3305I 517 82, Email yss@cpu.edu.cn

Received: December 28, 2017 | Published: January 05, 2018

responsive to each other, have a big combination, make connections to professional practices and organizational capabilities, facilitate the collaboration which both lead to a modern development and create a harmony between the innovation goals and the social and public goals. Moreover, this helps and stimulates the spread of harmony between the productive community and the public as well as develop a spirit of trust and love in society which lead to a balance of benefits. Sometimes, the more we have innovations in our daily life the more the public and the people can be affected and can have unwanted social effects. Indeed, a lot of workers might lose their jobs and be replaced with new machines, the RI is coming to make an end to this dilemma which can make the people vulnerable to the unemployment, the main major objective of RI is to handle and promote the responsibility in order to guarantee that the new innovated tools can not affect our life quality and will not negatively affect our coming generations. ${ }^{6}$

If we want to live a comfortable and harmonized life, the only way is to refer to the responsibility and the ethical ways when dealing with everything regardless of which work we are doing. Indeed, we are aware that performing tasks with sincerity, honesty, with rational and moral standards will have satisfactory results which will be reflected positively to our social, economic and modern development and success because the RI is the key that opens the prosperity doors.

\section{Acknowledgements}

We acknowledge the Jiangsu Overseas Research \& Training Program for University Prominent Young \& Middle-aged Teachers. Kadour Ghanemi is the recipient of a full scholarship from the China Scholarship council.

\section{Conflict of interest}

The authors declare that there is no conflict of interest.

\section{References}

1. Ribeiro BE, Smith RDJ, Millar K. A mobilising concept? unpacking academic representations of responsible research and innovation. Sci Eng Ethics. 2017;23(1):81-103. 
2. Pavie $X$. The importance of responsible innovation and the necessity of 'innovation-care'. Philos of Manag. 2014;13(1):21-42.

3. Scholten VE, van der Duin PA. Responsible innovation among academic spin-offs: how responsible practices help developing absorptive capacity. Journal on Chain and Network Science. 2015;15(2):165-179.

4. Ghanemi K, Yan S. Companies and responsible innovation: toward a long-term success. MOJ Public Health. 2017;6(4):00176.
5. Stilgoe J, Owen R, Macnaghten P. Developing a framework for responsible innovation. Research Policy. 2013;42(9):1568-1580.

6. Owen R, Jack Stilgoe, Phil Macnaghten, et al. A Framework for Responsible Innovation, in Responsible Innovation. USA: John Wiley \& Sons, Ltd; 2013:27-50. 